\title{
The influence of different cutting parameters on the glass edge quality
}

\author{
Xiaoyu Li*1, a, Liangbao Jiang*1, b, Minbo Wang, ${ }^{1, \text { c }}$, Jiaxi Liu ${ }^{1, \mathrm{~d}}$, Jiaming $\mathrm{Li}^{1, \mathrm{e}}$ and Yue Yan*1, f \\ ${ }^{1}$ Beijing Institute of Aeronautical Materials, Beijing 100095, China
}

\begin{abstract}
The influence of different cutting parameters on the glass edge quality was investigated, including the cutter material, the sharpening angle of the cutting roll, the cutting speed and the load applied to the roll. The results show that there are less defects on the edge of the glass cut by diamond cutter. There is no obvious influence of cutting speed on the glass edge quality. The cutter with a smaller sharpening angle is more applicable for the cutting of thin glass, and the thick glass is more suitable to use a bigger sharpening angle cutter. Higher cutting load is helpful for the breaking of the glass along the cutting line. However, it may cause more defects on the edge and the surface of the glass.
\end{abstract}

\section{Introduction}

There are numerous methods for glass cutting, including cutting with laser beam, waterjet cutting, hot airjet cutting or mechanical cutting with a roll cutter [1]. The most simple and accessible way is the mechanical method, that is, generating a cutting line on the glass surface with a hard-alloy or diamond roll cutter, and then break the glass along the cutting line. The cutting parameters including the material of the roll cutter, sharpening angle of the roll cutter, cutting speed and cutting load have different influence on the glass edge quality. The glass edge can be free of defects with a proper cutting parameter. Otherwise, there can be numerous defects, such as chips, scars and notches on the edge and the surface of the glass [2]. These defects have an obvious influence on the glass strength [3]. Different glass requires different cutting parameters according to the glass property. Thus, it is meaningful to investigate the optimum cutting parameters for glasses with different ingredient and thickness.

In this paper, we take the aluminosilicate and lithium aluminosilicate glass as research object, aiming at researching the influence of different cutting parameters on the glass edge quality. The influence of the material and sharpening angle of the roll cutter, the cutting speed and cutting load are investigated. The edge and the surface of the glass after cutting are observed to estimate the cutting effect.

\section{Experimental procedure}

Four different kinds of glass were used in this work, including two kinds of aluminosilicate glass produced by Corning Corporation (New York, U.S.) and Aureavia Hitech Company (Chongqing, China), separately, and two kinds of lithium aluminosilicate glass produced by Aureavia Hi-tech Company (Chongqing, China) and Sichuan Xuhong Optoelectronic Technology Company (Sichuan, China), separately. An electric cutting machine (LDQG-2525) produced by Lidu Glass Machinery Company was used to investigate the influence of cutting parameters on the glass edge quality. The edge and surface morphology were observed with an optical microscopy.

\section{Results and discussions}

Figure 1 shows the glass edge quality dependence of roll cutter materials. Normally used hard alloy and diamond cutter were applied to cut the glass separately. Four different kinds of glass, including two kinds of aluminosilicate glass and two kinds of lithium aluminosilicate glass were chosen to analyze the influence of cutter material on glass edge quality. The difference between the four glasses was also shown in Fig.1. The morphology of the cutting edge and surface was observed with an optical microscopy after cutting. From Fig.1, it can be seen that the glass edges cut with diamond cutter show less defects than that with hard alloy cutter. Different kinds of glass show similar results. The diamond roll cutter is better for reducing the defects on the glass edge and surface. 


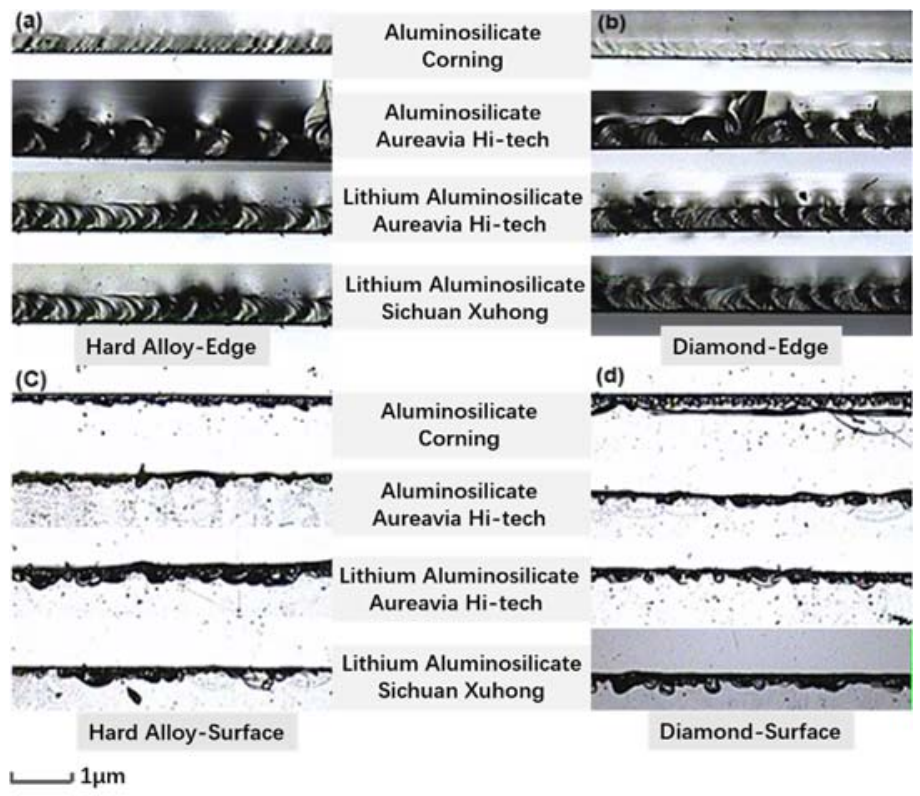

Fig. 1 The glass cutting quality dependence of roll cutter materials: (a) the edge and (c) surface of hard alloy cutter; (b) the edge and (d) surface of diamond cutter

(a)

(b)

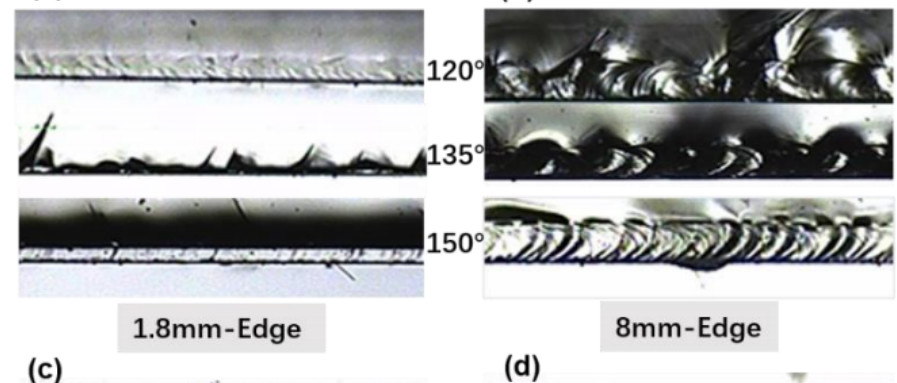

(c)

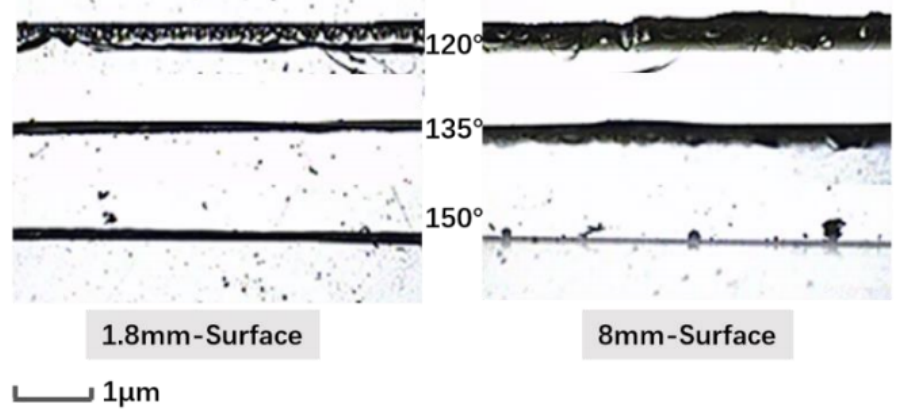

Fig. 2 The glass cutting quality with different sharpening angle of roll cutter: (a) the edge and (c) surface of thin glass; (b) the edge and (d) surface of thick glass

Figure 2 shows the influence of different cutter angle on the glass edge quality. Diamond roll cutter with three different angle $\left(120^{\circ}, 135^{\circ}\right.$ and $\left.150^{\circ}\right)$ were used to cut the glass. Two different thickness $(1.8 \mathrm{~mm}$ and $8.0 \mathrm{~mm})$ of glass from Corning Corporation were investigated. The cutting speed and load were fixed to $26 \mathrm{~m} / \mathrm{min}$ and $25 \mathrm{~N}$ for all the experiments, separately. From Fig.2 (a), it can be seen that the edge is more smoothly with a small cutter angle for the thin glass. However, it shows an opposite trend for the thick glass. Thus, roll cutter with a small angle is more applicable for the cutting of thin glass, and the thick glass is more suitable to use a big angle cutter. 
(a)

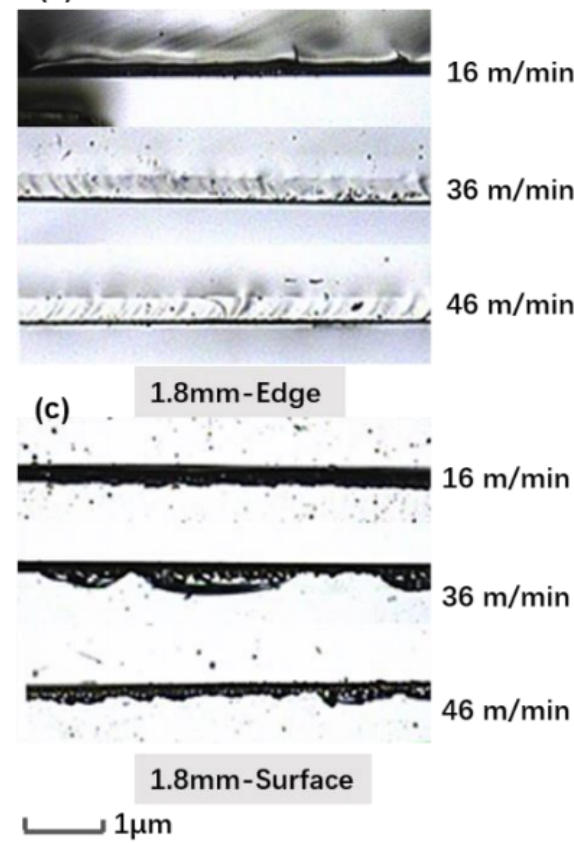

(b)

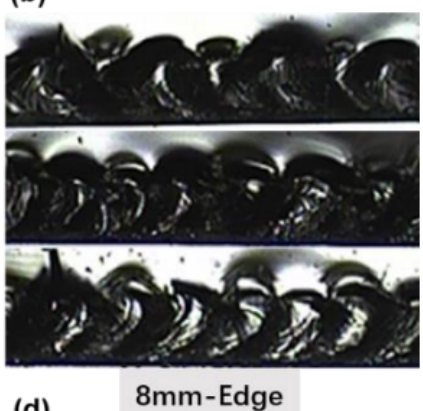

(d) $8 \mathrm{~mm}-$ Edge

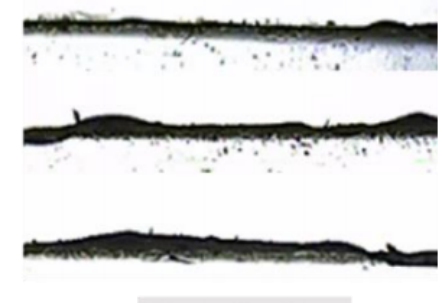

$8 \mathrm{~mm}$-Surface

Fig. 3 The glass cutting quality with different cutting speed: (a) the edge and (c) surface of thin glass; (b) the edge and (d) surface of thick glass

(a)

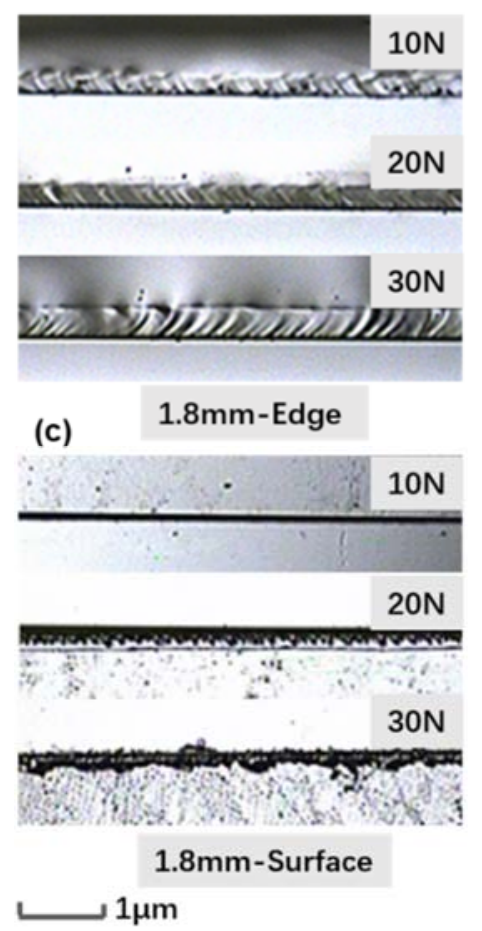

(b)

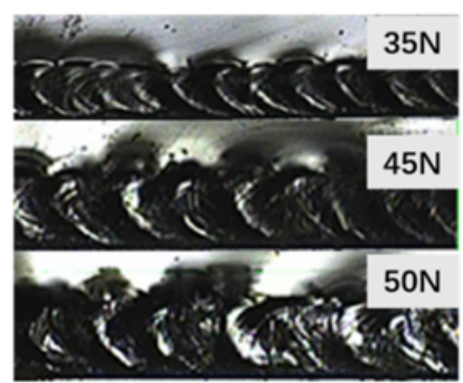

(d)

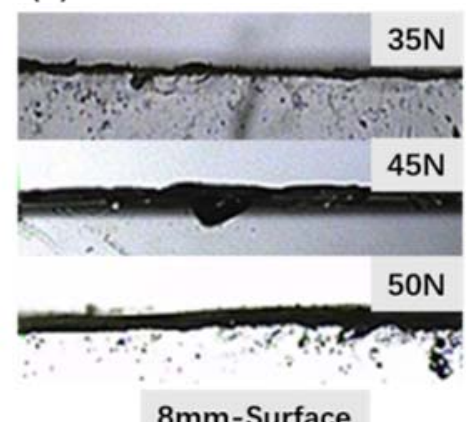

$8 \mathrm{~mm}$-Surface

Fig. 4 The glass cutting quality with different cutting load: (a) the edge and (c) surface of thin glass; (b) the edge an

d (d) surface of thick glass

Figure 3 and figure 4 shows the influence of different cutting speed and load on the glass edge quality, separately. A diamond roll cutter with an angle of $120^{\circ}$ was used to cut the glass. Two different thickness $(1.8 \mathrm{~mm}$ and $8.0 \mathrm{~mm})$ of glass from Corning Corporation were investigated. For the analysis of cutting speed, the cutting load was fixed to $25 \mathrm{~N}$ for all the experiments. The cutting speed was set as $16 \mathrm{~m} / \mathrm{min}, 36 \mathrm{~m} / \mathrm{min}$ and 46 $\mathrm{m} / \mathrm{min}$, separately. For the analysis of cutting load, the cutting speed was fixed to $26 \mathrm{~m} / \mathrm{min}$. The cutting load was set as $10 \mathrm{~N}, 20 \mathrm{~N}, 30 \mathrm{~N}$ for the thin glass $(1.8 \mathrm{~mm})$ and as $35 \mathrm{~N}, 45 \mathrm{~N}, 50 \mathrm{~N}$ for the thick glass $(8.0 \mathrm{~mm})$.

From Fig.3, it can be seen that there is no obvious difference between the edges and surfaces with different cutting speed. The thick glass shows a more roughly edge and bigger defect size than the thin glass. From Fig.4, it is obvious that the cutting depth and the size of defects both on the edge and surface increasing with the increase of cutting load. It is easier to break the glass along the cutting line with a higher cutting load. However, the edge and surface quality deteriorated with 
the increasing of cutting load, and lateral cracks formed. It is reported that the defects such as chips and notches on the upper surface have a significant effect on the glass strength. A higher cutting load may result in a lower glass strength [3]. In addition, thick glass needs higher cutting load. Thick glass cannot break along the cutting line when the cutting load is below $35 \mathrm{~N}$. This may be attributed to the fact that low cutting load cannot produce sufficient median crack depth [4].

\section{Summary}

The influence of different cutting parameters on the glass edge quality was investigated, including the cutter material, the sharpening angle of the cutting roll, the cutting speed and the load applied to the roll. The results show that there are less defects on the edge of the glass cut by diamond cutter. There is no obvious influence of cutting speed on the glass edge quality. The cutter with a smaller sharpening angle is more applicable for the cutting of thin glass, and the thick glass is more suitable to use a bigger sharpening angle cutter. Higher cutting load is helpful for the breaking of the glass along the cutting line. However, it may cause more defects on the edge and the surface of the glass. It is necessary to maintain the optimum cutting parameters in order to accomplish high-quality glass cutting.

\section{References}

1. Nisar S, Sheikh L L A. Laser glass cutting techniques-A review[J]. Journal of Laser Applications, 2013, 25(4):11.

2. Kondrashov V I, Shitova L A, Litvinov V A, et al. Characteristics of Cutting Parameters and Their Effect on the Glass Edge Quality[J]. Glass and Ceramics, 2001, 58(9):303-305.

3. Shitova L A, Lalykin N V, Kuznetsova T A. Glass edge quality and strength[J]. Glass \& Ceramics, 1991, 48(8):327-329.

4. Lindqvist $M$, Lebet $J$ P. Strength of glass determined by the relation of the critical flaw to the fracture mirror[J]. Engineering Fracture Mechanics, 2014, 119:43-52. 